\title{
Electric vehicle technology impacts on energy
}

\author{
Wael A. Salah ${ }^{1}$, Basim Alsayid ${ }^{2}$, Mahmoud A. M. Albreem ${ }^{3}$, Basem Abu Zneid ${ }^{4}$, Mutasem \\ Alkhasawneh ${ }^{5}$, Anwar Al Mofleh ${ }^{6}$, Anees Abu Sneineh ${ }^{7}$, Amir Abu Al Aish ${ }^{8}$ \\ ${ }^{1,2,7}$ Department of Electrical Engineering, College of Engineering and Technology, \\ Palestine Technical University-Kadoorie (PTUK), Palestine \\ ${ }^{3}$ Department of Electronics and Communication Engineering, College of Engineering, \\ A'Sharqiyah University (ASU), Oman \\ ${ }^{4}$ Faculty of Electrical and Computer Engineering, University Of Business and Technology CEiT \\ Dhaban-North Jeddah, Saudi Arabia \\ ${ }^{5}$ Faculty of Information Technology, Software Engineering Department, Ajloun National University, Jordan \\ ${ }^{6}$ Faculty of Engineering Technology, Al-Balqa' Applied University, Jordan \\ ${ }^{8}$ Communication Engineering Department, Faculty of Engineering, Al-Hussein Bin Talal University, Jordan
}

\section{Article Info \\ Article history: \\ Received Mar 24, 2018 \\ Revised Sep 13, 2018 \\ Accepted Sep 30, 2018}

\section{Keywords:}

Clean energy

Electric vehicle

Emission

Environment

Inverter

Motor control

Sustainable energy

\begin{abstract}
The $\mathrm{CO}_{2}$ emission level is becoming a serious issue worldwide. The continuous increase in gasoline price forms the essential base of development of electric vehicle (EV) drives. Moreover, economic and environmental issues relate to fabrication and operation of traditional powered vehicles. The basic considerations and development perspectives of EVs are presented in this paper. The development of an efficiently designed motor and drive satisfy the need of efficient characteristics that enable EVs to perform as part of the propulsion unit. The use of digital signal controllers compared with conventional control systems minimizes the motor's total harmonic distortion, lowers operating temperatures, and produces high efficiency and power factor ratings. This paper addresses the view of EV technology as well its advantages over other technologies.
\end{abstract}

Copyright (C) 2019 Institute of Advanced Engineering and Science. All rights reserved.

\section{Corresponding Author:}

Wael A. Salah,

Department of Electrical Engineering, College of Engineering and Technology,

Palestine Technical University-Kadoorie (PTUK),

P.O. Box: 7, Yafa Street, Tulkarm, Palestine.

Email: waelsalah.dr@gmail.com, wael.salah@ptuk.edu.ps

\section{INTRODUCTION}

Electric vehicle (EV) drives, which are generally subjected to frequent start and stop demands, are used in different climates, road conditions, and terrains. EV drives used mainly in industrial production lines are often operated at constant speeds and in controlled environments. In any EV propulsion unit, the motor drive is the most important part. The drive system mainly consists of an electric motor, a power converter, and an electronic controller. The motor drive should be designed to satisfy several characteristics, such as high torque capability, high efficiency, regenerative braking, and good thermal and cooling systems, which enable it to perform efficiently as part of the propulsion unit. Electric and hybrid vehicles are important factors for the improvement of a healthy environment owing to their beneficial effect on the environment through low $\mathrm{CO}_{2}$ emission level. With the steadily increasing oil prices, the need for alternative energy source is growing. Electric and electric hybrid vehicles offer the best possibility for the use of new alternative energy sources. 
Electric drive refers to the conversion of electrical to mechanical energy in executing various work demands and processes. About 50\% of electrical energy produced is used by electric drives. Approximately $75 \%-80 \%$ of these electric drives operate at constant speed owing to the minimal requirement for speed control in their application. The remaining 20\%-25\% requires electric drives that can respond to variable speed and torque to match the mechanical load [1]. The variable speed drive (VSD) is now popular even in industrial and home appliances [2]. The market of motion controls products shows a viable growth. Motion control market growth is illustrated in the histogram in Figure 1. This growth reflects that the demand for DC commutator motor drive sales decreases in contrast to the significant annual increase in AC motor drives [3].

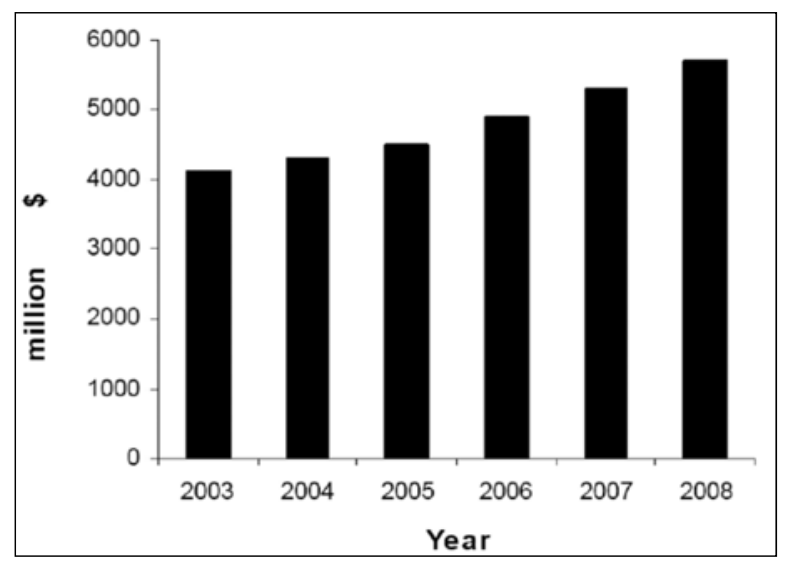

Figure 1. Motion control market growth [3]

Owing to the rapid technological advancement in power electronic converters, AC motors are increasingly becoming attractive solutions for variable speed applications and have recorded steady growth since 1990. Figure 2 shows a major shift from traditional variable-speed DC brushed motors, which have been used for decades [4]-[6].



Figure 2. AC versus DC electric drive market [1]

Electrical machines are key equipment in many industrial processes. They work either under constant or variable speed to match the unknown load torque operation. A feedback control loop must be implemented through a VSD. Information on the actual electrical and mechanical operating conditions experienced by the motor is provided and sensed by variable appropriate sensors. Then, a control algorithm processes this information and compares it with the demanded reference speed/torque. Based on this comparison, the supplied voltage or current to the motor windings is controlled through the power electronics switches as shown in Figure 3.

Int J Pow Elec \& Dri Syst, Vol. 10, No. 1, March 2019 : 1 -9 


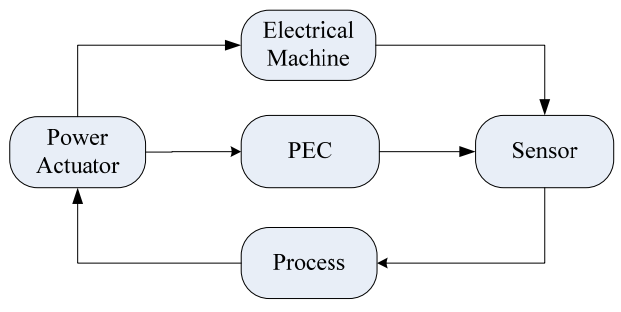

Figure 3. General scheme of VSD

The high maintenance requirement of the DC motor is a persistent problem with the DC drives. The AC VSDs have become popular and have rapidly grown since the 1980s. This growth is mainly a result of advances in power electronic switches and digital control technologies that highly affected the cost and performance of different VSD systems. The main performance parameter of pulling the movement toward $\mathrm{AC}$ VSDs is the rugged reliability and low cost of AC motors compared with the traditionally used DC brushed motor. The mechanical commutation system in the DC brushed motor is the major source of inefficiency of DC drives. It has been replaced by a power electronic converter circuit called the inverter to validate the AC VSD system. Nevertheless, the uses of power electronics devices require a sensitive and efficient digital control, which is the main difficulty in the AC VSD systems. This type of control complicates the system and increases the cost in achieving a reliable inverter circuit.

For any new technology proposed, the energy efficiency could attract new customers and help commercialize it among public users [7]. The wide presence of power electronics converter (PEC) systems has recently caused the energy savings to pay back for the additional expenses implied by VSD implementation. Energy costs, interest rates, and inflation rise slowly every year, but this increasing cost could be forestalled to some extent by energy saving through PEC. Given that the life span of PEC drives ranges from 10 to 15 years, the principal investment in installing the PEC pays off well during this cycle. The energy savings produced by the PEC in VSDs for the PEC and motor improve energy utilization [8].

Regardless of the types of motor that the electrical drives are driving, the programmable microcontrollers inside the drive controller enable intelligent controls over stator and rotor flux angles, total harmonic distortion (THD) and power factor correction for optimal efficiency, and high-pitched noises associated with conventional PWM controllers [9].

In consideration that the electric motor is the heart of electric vehicles (EVs), the recent advances in electrical machines and their control greatly affect the development of EVs, particularly the development of $\mathrm{AC}$ drives and the production of highly efficient AC motors. Different types of electric motors have been used by manufacturers to implement different electric vehicles models as part of the drive system. Table 1 shows the different models of EVs by various manufacturers that are listed along with the type of motor used to implement the EV [10]. The table shows that the AC motors are primarily used in EV implementation. The permenant magnet PM brushless motors are specifically used owing to their dynamic characteristics and low maintenance compared with other commonly used AC motors.

Table 1. Motors used in electric vehicles [10]

\begin{tabular}{lll}
\hline \multicolumn{1}{c}{ Company } & \multicolumn{1}{c}{ EV Model } & \multicolumn{1}{c}{ EV Motor } \\
\hline Fiat & Fiat Panda Electra & Series de motor \\
Fiat & Fiat Seicento Elettra & Induction motor \\
Honda & Honda EV Plus & PM BLDC motor \\
Mazda & Mazda Bongo & Shunt de motor \\
Nissan & Nissan Altra & PM BLDC motor \\
Toyota & Toyota RAV 4 & PM BLDC motor \\
General Motors & GM EVI & Induction motor \\
Ford & Ford Think City & Induction motor \\
\hline
\end{tabular}

\section{PROBLEM STATEMENT}

High dependence on the oil as the main source of energy for passenger vehicles has several effects because the number of automobiles introduced on the road increases annually. An economic factor is also inherent in the poor energy conversion efficiency of combustion engines, but the use of EVs is still very limited compared with other types of commonly used and manufactured vehicles. One reason could be that electric cars remain more expensive than traditional cars. The high expense mostly refers to their expensive batteries. Furthermore, concerns relate to sufficiency of battery charge before traveling great distances. 
For example, the transportation sector in Malaysia is considered one of the most advanced among developed countries in Asia. The fossil fuel types used in the transportation sector include natural gas, aviation gasoline, motor gasoline, aviation turbine fuel (ATF or Avtur), diesel oil, and fuel oil. Natural gas fuel is a mixture of gaseous hydrocarbons (mainly methane) that occur either in gas fields or in association with crude oil in oil fields. The transportation sector energy usage based on fuel types is given in Table $2[11]$.

Table 2. Energy structure according to fuel types used in the transportation sector of Malaysia

\begin{tabular}{lllllll}
\hline Year & & \multicolumn{5}{c}{ Fuel Type (ktoe) } \\
& Petrol & Diesel & ATF & Fuel oil & NG & Elect \\
\hline 1980 & 1296 & 847 & 250 & - & 0 & 0 \\
1985 & 2057 & 1032 & 386 & - & 0 & 0 \\
1990 & 2889 & 1826 & 628 & 41 & 0 & 0 \\
1995 & 4477 & 2168 & 1158 & 17 & 5 & 0 \\
1996 & 5161 & 2417 & 1333 & 32 & 4 & 1 \\
1997 & 5574 & 3106 & 1437 & 75 & 5 & 1 \\
1998 & 5849 & 2311 & 1618 & 9 & 4 & 1 \\
1999 & 6778 & 3174 & 1423 & 13 & 0 & 4 \\
2000 & 6378 & 4103 & 1574 & 4 & 7 & 4 \\
2001 & 6820 & 4534 & 1762 & 5 & 14 & 5.17 \\
2002 & 6940 & 4680 & 1785 & 5.5 & 28 & 5.20 \\
2003 & 7120 & 4732 & 1798 & 5.8 & 36 & 5.5 \\
2004 & 7531 & 4791 & 1815 & 6 & 44 & 6 \\
2005 & 7865 & 4812 & 1830 & 6.5 & 56 & 6.2 \\
\hline
\end{tabular}

(Source: Malaysian National Energy Balance, 2005) [11]

\subsection{Planning issue}

The growing numbers of passengers and vehicles in addition to increasing trip distances result in a visible increase in the energy used by propulsion vehicle systems. Private vehicle population grows annually, which increases energy consumption. With fossil fuel as the main source, air pollution increases because of combustion. Therefore, a high efficiency of energy use in the transport sector should be planned to minimize air pollution and address environmental concerns. Implementing energy efficient EV systems can help reduce the daily increase in petroleum oils used in the propulsion system. As a result, it can curb rising air pollution, especially $\mathrm{CO}_{2}$ emissions in which two-thirds originate from transport fuel combustion [12],[13]. The final consumption for petroleum as shown in Figure 4.

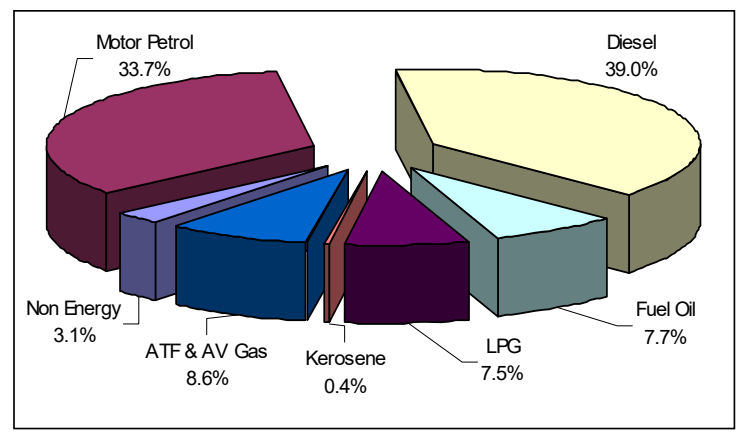

Figure 4. Final consumption for petroleum product (National Energy Balance 2003) [12]

\subsection{Financial issue}

Gasoline refined from crude oil is primarily used to supply the automobiles and light trucks with the required fuel to power their combustion engines [11]. The almost continuous increase in the cost of the gasoline is concerning. This issue could be addressed by development and implementation of an EV. The EV could be charged at home at night during non-peak hours because electricity is cheaper at night. Gasoline prices fluctuate even when crude oil prices are stable, thereby causing trouble and headache for customers. Factors that cause the price fluctuation normally stem from the seasonality local retail station competition and the crude oil supply disruptions [14].

Int J Pow Elec \& Dri Syst, Vol. 10, No. 1, March 2019 : $1-9$ 


\subsection{Environmental issue}

In addition to $\mathrm{CO}_{2}$ emissions, the traditionally powered gasoline vehicle usage results in other gas emissions that can highly affect the local air quality. Three gases covered by the Euro standards include carbon monoxide (CO), hydrocarbon (HC), and nitrogen oxides (NOx). A balanced policy that could reflect the effects of both local air quality change and global climate change is needed given the benefits and disadvantages of fuels [15]. The basic transportation $\mathrm{CO}_{2}$ sources as shown in Figure 5.

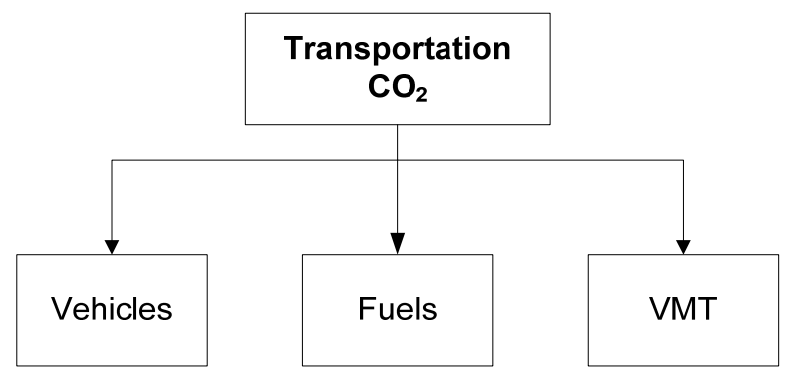

Figure 5. Transportation $\mathrm{CO}_{2}$ sources

The light-duty vehicle $\mathrm{CO}_{2}$ emissions are affected by vehicle use in terms of the vehicle miles traveled (VMT), fuel economy which refers to the miles per gallon, and the net greenhouse gas emissions [16]. The fuel economy is affected by the characteristics, operating conditions, and practices of the vehicle. VMT growth affects the mounting emissions originating from the light-duty vehicle [16]. Figure 6 shows a statistical graph of the amount of $\mathrm{CO}_{2}$ emissions from the transport sector in Asia, which clearly illustrates the gradually increasing emission level.

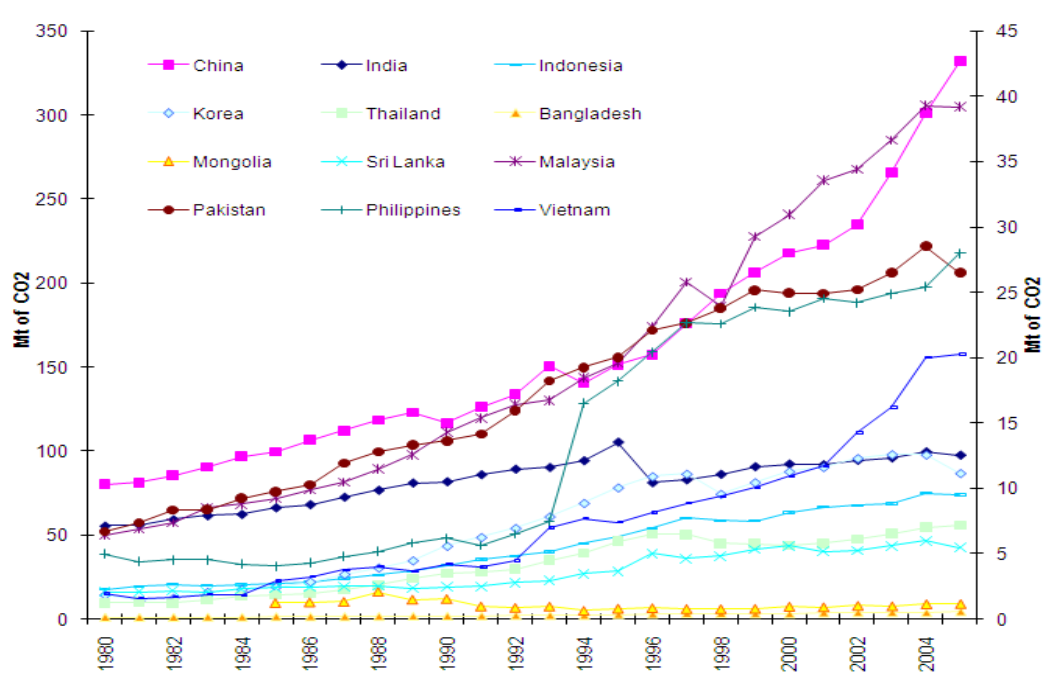

Figure 6. Trend of transport sector $\mathrm{CO}_{2}$ emissions in Asia (IEA, 2007) [17]

\subsection{Health issue}

Air pollution has a visible effect on human health and environment owing to harmful components. Air pollution components include $\mathrm{CO}$, sulfur dioxide ( $\mathrm{SOx}$ ), $\mathrm{NOx}, \mathrm{HC}$, and $\mathrm{CO}_{2}$. $\mathrm{CO}$ reduces the blood's capability to carry oxygen, aggravates lung and heart disease, and causes headaches, fatigue, and dizziness. The combination of SOx with water vapor in the air contributes to acid rain. NOx causes a yellowish-brown haze and becomes a poisonous gas that damages lung tissue if combined with oxygen. HC could cause cancer and could irritate mucous membranes. Excess $\mathrm{CO}_{2}$ can cause more sunlight to enter the atmosphere, which causes global warming. 
The key point to be addressed is that car sales have almost doubled in the past 25 years. This phenomenon has considerably increased the demand for considering an alternative solution to limit and/or minimize the emissions from these vehicles [18].

\section{EV DEVELOPMENT EFFECTS}

\subsection{Save money}

Fuel prices continue to climb with the increase in tariff rates of electric power. Thus, the challenge for saving energy has been arising and highly concerning at a global level along with the increase in car sales as shown in Figure 7. However, electricity remains much cheaper than gasoline because it is mostly locally generated. The massive increases in gasoline prices are unavoidable because its demand is quickly overtaking the world's normal production. Nevertheless, the electricity price has not changed significantly because the electricity is locally generated. It is also generated from renewable resources (solar, wind, biomass, and geothermal), which are slowly becoming much popular with the reduction of installation cost.

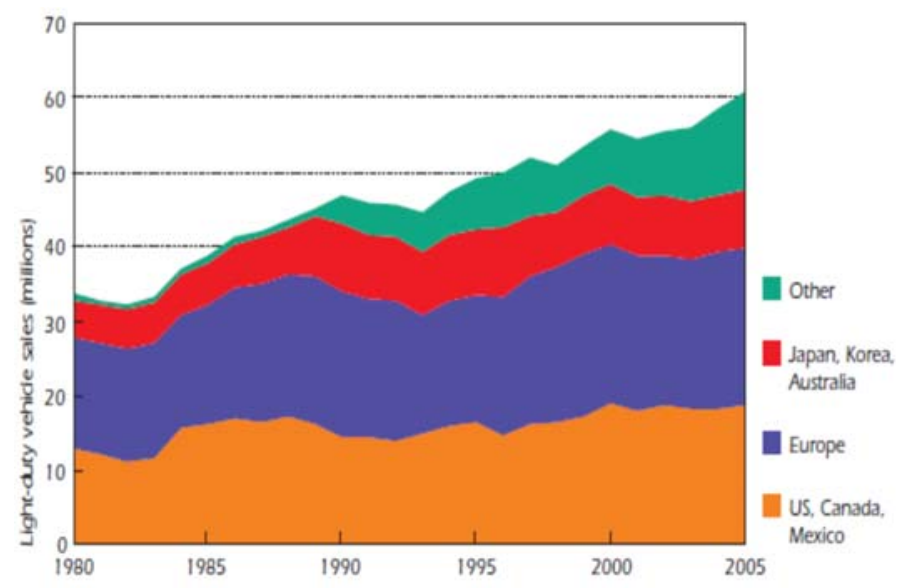

Figure 7. Global car sales (1980-2005) (IEA Data, 2007)

\subsection{Finite resources}

The global petroleum level is permanently dropping owing to resource constraints [11]. The available usable energy is a finite resource, and energy cannot be repeatedly used indefinitely. Despite large supplies of coal, oil, and natural gas, the demand is increasing, but the amount of new energy supplies being discovered is decreasing. The consumption of energy by fuel type illustrated in Figure 8 shows that worldwide energy use, especially the demand for oil, continuously increases.

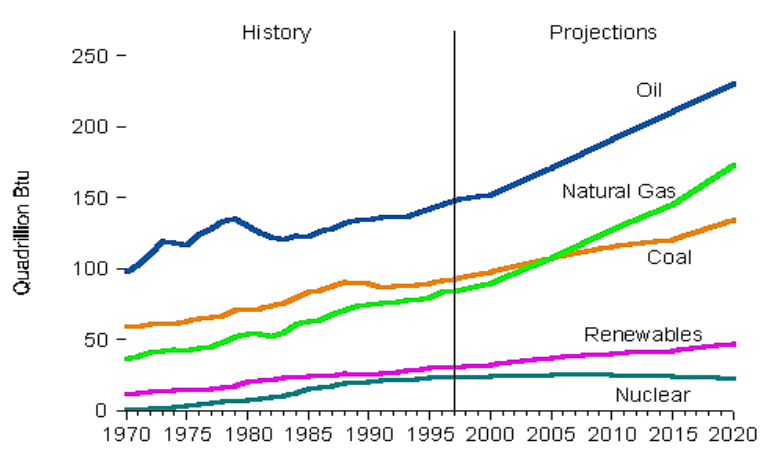

Figure 8. World energy consumption (EIA-International Energy Outlook 2000) 


\subsection{Clean environment}

Energy conservation and environmental protection are highly important concerns worldwide. The availability of electricity is a major consideration in EV development. In terms of environmental aspects, the EVs produce zero emission at the point of use, which results in significant reduction in air pollution in crowded town areas. Air pollution causes many harness effects on humans and surrounding environment. Therefore, quality air is a possible result of greenhouse effect. The rules and regulations that relate to practices that could affect the environment are important to encourage the promotion and movement of EVs. Some cities have implemented emission-free zones from all sources that mostly come from transport. World carbon emissions statistics are shown in Figure 9. The graph clearly shows the visible increase in carbon emissions worldwide.

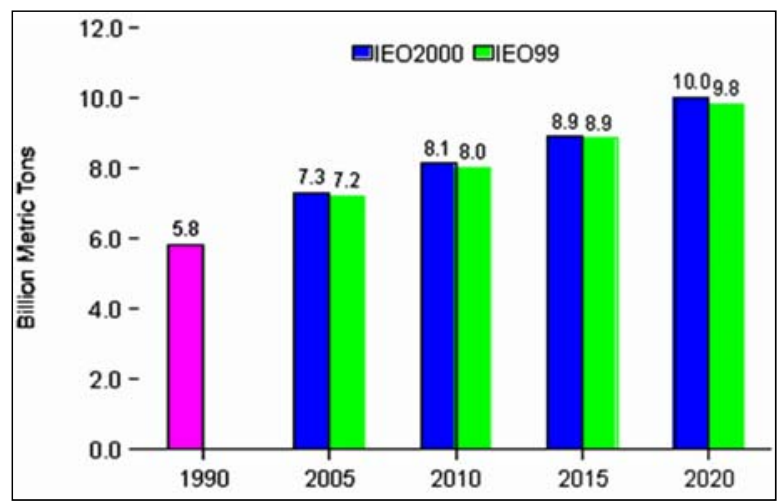

Figure 9. World carbon emissions (EIA-International Energy Outlook 2000)

EVs benefit environmental protection owing to improvement in air quality, reduction in noise level, and zero local exhaust emissions. Globally, the emission from the generation of electricity for EVs is only $2 \%$ in $\mathrm{CO}$, whereas that in gasoline-powered vehicles is about $76 \%$ in $\mathrm{CO} 2,56 \%$ in NOx, and $9 \%$ in $\mathrm{HC}$. EVs operate quietly and almost vibration-free, whereas gasoline-powered vehicles are inherently noisy and have sensible vibration [19]. The EVs powered by high-efficiency controlled electric motors supplied by alternative energy sources are somehow clean, efficient, and environmentally friendly town transportation systems.

Moreover, the efficient potential pollution problem suppression by using the EVs has zero emissions. The aspects that influence the pattern and emission level of energy consumption from the transportation sector of Malaysia are presented. The study concludes that the total energy demand and vehicular emissions from the road transport represent one of the greatest areas of challenge for energy efficiency [20]. The increasing usage of petrol is primarily from the consumption in the transportation sector. Petrol has been recently replaced by other fuels partially or totally in other sectors, yet the world energy demands continue growing with the population. The development of new technologies helps decrease fuel consumption in the transportation sector, which still accounts for the siginificant amount of air pollution in cities.

\section{EV APPLICATIONS AND MARKET}

EVs are used for passengers and public transportation. EVs are successfully realized in off-road vehicles market as they fulfill the application requirements. These applications include airport vehicles for passenger and ground support, recreational vehicles such as golf carts, plant operation vehicles such as forklifts and loader trucks for theme parks, vehicles for disabled persons, and so on. [21]. EVs are cost effective and lean toward green technologies. In addition, EVs have received increasing interest because they contribute to global pollution reduction. To achieve the abovementioned objectives, the following infrastructure matters should be considered: (a) Battery chargers: implementation of residential and public charging facilities and stations; (b) Standardization of EV plugs, cords, and outlets and safety issues; (c) Sales and distribution; (d) Service and technical support; and, (e) Supply of parts. However, cost remains a major concern, and EV initial cost and battery replacement cost must be suppressed at a reasonable level. 


\section{EV IMPLEMENTATION}

Figure 10 shows the basic EV propulsion system. Batteries or fuel cells can generally be used as energy system in EVs [22].

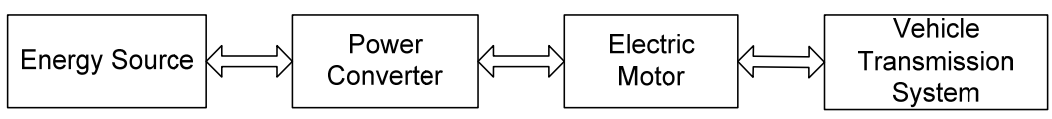

Figure 10. Basic electric vehicle propulsion system

\subsection{Electric vehicle technologies}

The essential technologies for EVs are: EV, hybrid, and fuel cell vehicles. Batteries are used as energy storage that powers the electric motor of the EV to achieve zero emissions. Batteries and conventional gasoline are used to power hybrid gas/EVs for propulsion. The hybrids generate less tailpipe emissions than the gasoline counterpart. The development of fuel cells could boost the EVs through generating electricity onboard, which is an emission-free source [12]. The main difference between EV technologies is the method used to generate the electricity that powers the electrics motors.

\subsection{Battery EVs and fuel cell vehicles}

A major concern of any new technology nowadays is energy storage [23]. Some energy storage technologies can be implemented commercially at small-scale integration, but others must be further developed. The study highlights the challenges that prevent the commercial deployment of these energy storage technologies [23]. The Battery Electric Vehicle (BEV) is a promising technology, but it still needs to be be developed to gain social acceptance. This study reviews the technological readiness of the BEV technology and highlights the main technological issues to be handed for visible progress [24]. BEVs have higher efficiency and are more commercial compared with fuel cell vehicles (FCVs). BEVs and FCVs are the only two zero-emission candidates [25].

\subsection{EV energy sources}

Energy efficiency, energy utilization, and environmental protection have attracted increasing concern in research and industry because of energy cost. A part of this major concern is to achieve a green energy efficient transportation system through implementation of EVs. The popularization of EVs on the road and the energy sources are key technologies that could possibly realize the commercial implementation of EVs. The storage system implemented in an EV should fulfill the requirement of high power density to accomplish its anticipated driving range. Typical energy storage devices for automotive applications are leadacid, nickel metal hydride, and lithium ion batteries [26]. Charging EVs using photovoltaic (PV) has been proposed [27]. The following approaches are available. The first is a combination of PV and the grid, and the second is using PV as the source only, which is more popular. The final aim is to reduce the emission over the entire life of a vehicle, including the energy and material used to power it [28]. The fuel cell operates in an electrochemical process that converts chemical energy into electrical energy. The fuel cell system has zero emission because it does not emit any exhaust gas. The wastage of the reaction results in the production of only water and heat [29].

\section{CONCLUSIONS}

The instability of gasoline prices is a compelling impetus for the development of EV drives. EV drives are essential and play major roles in economic and environmental issues. The design and development of an efficient motor drive aim to satisfy the characteristics needed to perform as part of the propulsion unit. This major aim can be realized by using digital signal controllers as replacement of the conventional control systems to minimize motor THD, lower operating temperature, increase efficiency, and improve power factor rating. The vehicles used by the majority of the population have become part of our daily life. The high percentage of carbon emissions from the exhaust of these vehicles comes from the conventional internal combustion engine. The issue is more serious in a town area where the vehicles are the major sources of pollution that cause greenhouse effect. EVs can indirectly affect carbon emissions at the power plant level. Strict standards of $\mathrm{CO} 2$ power plant emission levels can minimize this effect and thus reduce air pollution. The concerns on energy efficiency and energy consumption become more active to protect the environment. The best alternative solution for road transportation is the use of EVs. The development of energy source 
supplies for long-term drives is the crucial technology for commercialization and popularization of EVs. This paper demonstrates the potential of EVs in vehicular usage and practicability to fulfill the world's growing demand on energy without affecting environment air quality

\section{REFERENCES}

[1] I. Boldea and S. A. Nasar, "Electric drives," Boca Raton, Fla.: CRC/Taylor \& Francis, 2006.

[2] A. A. Sneineh and W. A. Salah, "Modelling of a high-speed precision robot for microelectromechanical systems bonding process application," Maejo International Journal of Science and Technology, Article vol. 12, no. 1, pp. 51-69, 2018.

[3] J. F. Gieras and SpringerLink, Advancements in Electric Machines. Available: http://dx.doi.org/10.1007/978-14020-9007-3, 2018.

[4] N. Mohan, "Electric drives : an integrative approach," Minneapolis: MNPERE, 2003.

[5] M. H. Rashid, "Power electronics : circuits, devices, and applications," Upper Saddle River, N.J.: Pearson/Prentice Hall, 2004.

[6] T. o. Wildi, "Electrical machines, drives, and power systems," Upper Saddle River, N.J.: Pearson/Prentice Hall, 2006.

[7] W. A. Salah, A. Al-Mofleh, and S. Taib, "Energy efficiency practices in power supplies: Scenario and solution," Energy Sources, Part B: Economics, Planning, and Policy, vol. 11, no. 2, pp. 182-190, 2016/02/01 2016.

[8] D. Polka, "Motors and drives : a practical technology guide," Research Triangle Park, NC: ISA, 2003.

[9] "Analog Technologies, Semiconductors, Digital Signal Processing," Texas Instruments (TI), 2006.

[10] N. Gaurav and C. K. Narayan, "A Survey and Comparison of Characteristics of Motor Drives Used in Electric Vehicles," in Electrical and Computer Engineering, 2006. CCECE '06. Canadian Conference on, pp. 811-814, 2006.

[11] National Energy Balance, Ministry of Energy, Communications and Multimedia, Kuala Lumpur, Malaysia, 2005.

[12] National Energy Balance, Ministry of Energy, Communications and Multimedia, Kuala Lumpur, Malaysia, 2003.

[13] Economic Planning Unit, The Malaysian Economic in Figures, Economic Planning Unit, Prime Minister's Department, Putrajaya, Malaysia, 2004.

[14] "The Energy Information Administration (EIA), http://www.eia.doe.gov."

[15] K. Liaskas, G. Mavrotas, M. Mandaraka, and D. Diakoulaki, "Decomposition of industrial $\mathrm{CO}<$ sub $>2</$ sub $>$ emissions: The case of European Union," Energy Economics, vol. 22, no. 4, pp. 383-394, 2000.

[16] R. J. Kopp, "Transport Policies to Reduce $\mathrm{CO}_{2}$ Emissions from the Light-Duty Vehicle Fleet. Issue Brief 12, RFFResources for the future environmental and natural resource worldwide policymaking, available at: http://www.rff.org/Publications."

[17] G. R. Timilsina and A. Shrestha, "Transport sector CO2 emissions growth in Asia: Underlying factors and policy options," Energy Policy, doi: DOI: 10.1016/j.enpol.2009.06.009 vol. 37, no. 11, pp. 4523-4539, 2009.

[18] IEA (2007). International Energy Agency (IEA) Database Vol., Release 01, 2007.

[19] K. T. Chau, Y. S. Wong, and C. C. Chan, "An overview of energy sources for electric vehicles," Energy Conversion and Management, vol. 40, no. 10, pp. 1021-1039, 7// 1999.

[20] A. Al-Mofleh, S. Taib, and W. A. Salah, "Malaysian energy demand and emissions from the transportation sector," Transport, vol. 25, no. 4, pp. 448-453, 2010.

[21] I. Husain, Electric and hybrid vehicles: design fundamentals. CRC press, 2011.

[22] C. C. Chan, "The state of the art of electric and hybrid vehicles," Proceedings of the IEEE, vol. 90, no. 2, pp. 247-275, 2002.

[23] M. Aneke and M. Wang, "Energy storage technologies and real life applications - A state of the art review," Applied Energy, Review vol. 179, pp. 350-377, 2016.

[24] A. Mahmoudzadeh Andwari, A. Pesiridis, S. Rajoo, R. Martinez-Botas, and V. Esfahanian, "A review of Battery Electric Vehicle technology and readiness levels," Renewable and Sustainable Energy Reviews, Review vol. 78, pp. 414-430, 2017.

[25] The Electric Auto Association (EAA), 2008, available at: www.eaaev.org.

[26] B. K. Tan, N. M. L. Tan, and A. K. Ramasamy, "Design of a battery-ultracapacitor hybrid energy-storage system with power flow control for an electric vehicle," International Journal of Power Electronics and Drive Systems (IJPEDS), Article vol. 9, no. 1, pp. 286-296, 2018.

[27] A. R. Bhatti, Z. Salam, M. J. B. A. Aziz, and K. P. Yee, "A comprehensive overview of electric vehicle charging using renewable energy," International Journal of Power Electronics and Drive Systems (IJPEDS), Article vol. 7, no. 1, pp. 114-123, 2016.

[28] J. Y. Yong, V. K. Ramachandaramurthy, K. M. Tan, and N. Mithulananthan, "A review on the state-of-the-art technologies of electric vehicle, its impacts and prospects," Renewable and Sustainable Energy Reviews, vol. 49, pp. 365-385, 2015.

[29] H. S. Das, C. W. Tan, and A. H. M. Yatim, "Fuel cell hybrid electric vehicles: A review on power conditioning units and topologies," Renewable and Sustainable Energy Reviews, vol. 76, pp. 268-291, 2017. 